\title{
Urine proteomics in the diagnosis of stable angina
}

\author{
Ulf Neisius ${ }^{1}$, Thomas Koeck², Harald Mischak ${ }^{1,2}$, Sabrina H. Rossi ${ }^{1}$, Erin Olson ${ }^{1}$, David M. Carty ${ }^{1}$, Jane A. Dymott ${ }^{1}$, \\ Anna F. Dominiczak ${ }^{1}$, Colin Berry ${ }^{1,3}$, Keith G. Oldroyd ${ }^{1,3}$ and Christian Delles ${ }^{1 *}$
}

\begin{abstract}
Background: We have previously described a panel of 238 urinary polypeptides specific for established severe coronary artery disease (CAD). Here we studied this polypeptide panel in patients with a wider range of CAD severity.
\end{abstract}

Methods: We recruited 60 patients who underwent elective coronary angiography for investigation of stable angina. Patients were selected for either having angiographic evidence of CAD or not (NCA) following coronary angiography ( $n=30 / 30$; age, $55 \pm 6$ vs. $56 \pm 7$ years, $P=0.539$ ) to cover the extremes of the CAD spectrum. A further 66 patients with severe CAD (age, $64 \pm 9$ years) prior to surgical coronary revascularization were added for correlation studies. The Gensini score was calculated from coronary angiograms as a measure of CAD severity. Urinary proteomic analyses were performed using capillary electrophoresis coupled online to micro time-of-flight mass spectrometry. The urinary polypeptide pattern was classified using a predefined algorithm and resulting in the $C A D_{238}$ score, which expresses the pattern quantitatively.

Results: In the whole cohort of patients with CAD (Gensini score 60 [40; 98]) we found a close correlation between Gensini scores and $\operatorname{CAD}_{238}(\rho=0.465, P<0.001)$. After adjustment for age $(\beta=0.144 ; P=0.135)$ the $C A D_{238}$ score remained a significant predictor of the Gensini score $(\beta=0.418 ; P<0.001)$. In those with less severe CAD (Gensini score $40[25 ; 61]$ ), however, we could not detect a difference in $C A D_{238}$ compared to patients with NCA $(-0.487 \pm 0.341$ vs. $-0.612 \pm 0.269, P=0.119)$.

Conclusions: In conclusion the urinary polypeptide $C A D_{238}$ score is associated with $C A D$ burden and has potential as a new cardiovascular biomarker.

Keywords: Coronary artery disease, Urinary proteomics, Stable angina

\section{Background}

Stable angina, with an estimated prevalence of $2-4 \%$ in most European countries [1], is a common disorder. Contemporary guidelines recommend assessment of patients with suspected angina with a variety of noninvasive tests for diagnostic purposes [1,2]. For reasons of availability, cost and test performance there is a need for new diagnostic tests to contribute to the diagnostic process of stable angina.

Recent advances in proteomics have allowed studies into new biomarkers of cardiovascular disease [3]. A

\footnotetext{
* Correspondence: Christian.Delles@glasgow.ac.uk

${ }^{1}$ BHF Glasgow Cardiovascular Research Centre, Institute of Cardiovascular and Medical Sciences, University of Glasgow, 126 University Place, Glasgow G12 8TA, UK

Full list of author information is available at the end of the article
}

variety of biofluids can be subject to proteomic analysis, yet for clinical applications urine has several advantages over blood [4]. Polypeptide expression patterns in urine can represent a "peptide finger print" of a disease and can therefore function as a disease specific biomarker.

We have previously developed a urinary proteome signature specific for coronary artery disease (CAD). An initial small study characterized a 15-biomarker panel with sensitivity and specificity to predict the presence of CAD of 98 and $83 \%$, respectively [5]. In our most recent study in a total of 623 individuals, a 238-biomarker panel in patients and controls from different centers was validated and filtered against concomitant disease and treatment-specific effects. The panel had a sensitivity of $79 \%$ and a specificity of $88 \%$ for the diagnosis of CAD 
[6]. The majority of CAD patients in this cohort had severe $\mathrm{CAD}$ and was scheduled for surgical revascularization.

Here, in a scenario closer to potential clinical use, we investigated whether the 238-biomarker panel $\left(\mathrm{CAD}_{238}\right)$ could also differentiate patients with less extensive CAD from patients without angiographic evidence of CAD (NCA).

\section{Methods}

\section{Study end points}

The primary end point of this study was the differentiation of significant CAD from NCA by the $\mathrm{CAD}_{238}$ score in patients with stable angina like chest pain. Secondary end points included: $\mathrm{CAD}_{238}$ score correlation with CAD extent/severity; evaluation of potential cofounding factors and assessment of the $\mathrm{CAD}_{238}$ scores capacity to identify prognostic relevant CAD.

\section{Patients}

Study participants were referred by local cardiologists for further investigations of typical symptoms and/or positive non-invasive tests to the Golden Jubilee National Hospital, Clydebank, UK, and underwent elective coronary angiography in 2009. From all patients $(n=1380)$ we selected those with significant $\mathrm{CAD}$, defined as at least one coronary artery stenosis $\geq 75 \%$ of the artery lumen; or NCA, defined as the absence of any angiographic evidence of CAD. Study visits took place in 2010, 286 (58 to 459) days after the coronary angiography/percutaneous intervention, and included urine sample collection. Patients were excluded for the following reasons: history of established CAD, acute coronary syndromes, previous organ transplantation, heart failure, malignant concomitant diseases within the last 5 years, systemic inflammatory diseases or severe liver diseases. Based on medical record information, residence within 13 miles of the study centre and availability of contact information, 260 eligible patients were invited of whom 87 agreed to participate (Additional file 1: Figure S1). Six patients had to be excluded following assessment at the study visit. Of the remaining participants, we selected a cohort of 30 patients with CAD and 30 age-matched patients with NCA for proteomic analysis.

Further cases and controls from a previous study [6] were included in the quantitative analyses in the present study in order to represent the spectrum of CAD from NCA to severe CAD requiring surgical revascularization. The cases consisted of patients with severe coronary artery disease confirmed by coronary angiography $(n=66)$ who were recruited at the pre-assessment clinic on the day prior to elective coronary artery bypass grafting (CABG). The controls were healthy volunteers without evidence of CAD $(n=67)$.
All participants gave written informed consent. The study was approved by the West of Scotland Research Ethics Committee and is in keeping with the principles of the Declaration of Helsinki.

\section{Gensini score}

To quantify the overall CAD extent the scoring system suggested by Gensini [7] was used. Stenoses of less than $25,25-49,50-74,75-94,95-99$ and $100 \%$ were equated with 1, 2, 4, 8, 16 and 32, accordingly. Depending on the artery segment and dominance of the left or right coronary artery, these scores were multiplied with factors from 0.5 to 5 [7] to implement the functional significance of the area supplied by that segment. The artery segment scores were finally added to obtain the Gensini score. If not stated otherwise, reported Gensini scores are based on angiographic findings prior to percutaneous intervention.

\section{Carotid intima media thickness}

Measurement of carotid intima media thickness was performed by ultrasonography (Acuson Sequoia C512, Siemens, Erlangen, Germany) with an $8 \mathrm{MHz}$ lineararray transducer. The carotid intima-media thickness of the left and right common carotid was measured in the far wall, $1 \mathrm{~cm}$ proximal of the carotid bulb in a plaque free region in accordance with the Mannheim consensus [8]. ECG signals were stored simultaneously to define the systolic and diastolic phase of the cardiac cycle. Offline measurements were performed semi-automatically at end diastole on B-mode images using Image-Pro Plus software, version 3.0 (Media Cybernetics, Bethesda, USA). Reported carotid intima-media thickness represents the mean of all taken measurements.

\section{Sample collection}

Routine urine and blood samples were collected according to local standards and analyzed in laboratories at Gartnavel General Hospital, Glasgow, UK. Urine samples for proteomics were stored at $-80{ }^{\circ} \mathrm{C}$ at the BHF Glasgow Cardiovascular Research Centre. Proteome analysis was carried out at Mosaiques Diagnostics, Hannover, Germany.

\section{Urinary proteomics}

All samples were prepared by ultrafiltration, desalting and lyophilisation, as described in detail previously [9]. Prior to CE-MS analysis, samples were resuspended with high performance liquid chromatography grade water to yield $0.8 \mathrm{~g} / \mathrm{L}$ protein concentration as measured by bicinchoninic acid assay (Interchim, Montlucon, France).

CE-MS analysis was performed as previously described [10] using a P/ACE MDQ capillary electrophoresis system (Beckman Coulter) online coupled to a time-of- 
flight mass spectrometer (micro-time- of-flight MS; Bruker Daltonic). Spectra were accumulated every $3 \mathrm{~s}$ over a range of mass-to-charge ratios from 350 to 3000 . Accuracy, precision, selectivity, sensitivity, reproducibility, and stability using this technique are described in detail elsewhere [9]. In brief, the detection limit is in the range of $1 \mathrm{fmol}$, depending on the ionization properties of the individual peptide. In a urine sample, the detection limit in the crude sample before processing is 100 to $1000 \mathrm{fmol} / \mathrm{mL}$. Platform validation was performed as described previously [11].

MosaiquesVisu (mosaiques diagnostics and therapeutics AG, Hannover, Germany) was employed for mass spectrometry data processing. Data were normalized based on reference signals from 29 abundant "housekeeping" peptides generally present in urine, which are the result of normal biological processes and are not affected by age, sex, or disease state [12]. The individual sample data were calibrated with a local regression algorithm and 29 internal standard peptides, all collagen fragments [12], as reference. After normalization signal intensity was employed as a marker for relative quantity.

\section{Statistics}

A power calculation $(1-\beta=0.95, \alpha=0.05)$ was conducted to evaluate the number of subjects necessary to detect a significant $\mathrm{CAD}_{238}$ score difference. Based on our previous data [6] (Additional file 1: Table S1) 12 patients in each group were required for the actual power 0.96. To account for any analytical difficulties we opted for a convenience sample of 30 patients per group.

Data were analyzed using SPSS software, version 15.0 (SPSS Inc., Chicago, USA). The $\mathrm{CAD}_{238}$ score corresponding to a CAD specific urinary polypeptide pattern was calculated as published by Delles et al. [6]. Normality of data distribution for all experiments was tested using the Kolmogorov-Smirnov test and visual inspection of Q-Q plots. Correlations were assessed by calculating Pearson's or Spearman's correlation coefficient for parametric and non-parametric data, respectively. The two sample Student's $t$ test or the Mann Whitney test was conducted as appropriate for the comparison of two groups of paired observations for continuous data. For comparison of categorical data of independent groups the Chi-squared test was employed.

\section{Results}

Cardiovascular risk factors were similar in patients with or without angiographic evidence of CAD (Table 1). Similarly, in patients with angina like chest pain the $\mathrm{CAD}_{238}$ score was not significantly different between patients with CAD and those with NCA $(-0.487 \pm 0.341$ vs. $-0.612 \pm 0.269, P=0.119)$ as shown in Fig. 1 . To adjust for potential cofounding factors we used a stepwise linear regression model with $\mathrm{CAD}_{238}$ score, age, gender and diabetes status as predictors of CAD. The resulting model contained only the $\mathrm{CAD}_{238}$ score $(\beta=0.206 ; P=0.090)$ and gender $(\beta=0.128 ; P=0.092)$, but remained statistically non-significant $(P=0.072)$.

In order to increase the sample size of our study and to cover a wider spectrum of severity of CAD for correlation analyses we added data from patients with severe $\mathrm{CAD}$ who were due to undergo CABG surgery (Additional file 1: Table S1). The complete CAD cohort ( $n=96$ patients) is summarized in Additional file 1: Table S2.

The Gensini score was different in patients with stable angina and CAD compared to CAD patients undergoing CABG (40 [25; 61] vs. 77 [56; 109]; $P<0.001)$. When all patients with $C A D$ were combined $(n=96)$ the $\mathrm{CAD}_{238}$ score correlated closely with the Gensini score $(\rho=0.465$, $P<0.001$; Fig. 2). Due to the difference in age between patients with CAD and stable angina and those prior to surgical coronary revascularization $(55.1 \pm 6.0$ vs. $64.3 \pm$ 8.8 years, $P<0.001$ ), we adjusted for age using a linear regression model. After adjustment for age $(\beta=0.144$; $P=0.135)$ the $\mathrm{CAD}_{238}$ score remained a significant predictor of the Gensini score $(\beta=0.418 ; P<0.001)$.

To evaluate if factors other than CAD severity influence the $\mathrm{CAD}_{238}$ score, we studied control subjects, i.e. those without evidence of CAD $(n=97)$ (Additional file 1: Table S2). Medication such as beta-blockers, statins, calcium channel blockers, aspirin or angiotensin converting enzyme inhibitors/angiotensin receptor blockers (Additional file 1: Figure S2) as well as cardiovascular risk factors such as hypertension (yes vs no, $n=35 / 58$, $-0.507 \pm 0.344$ vs $-0.518 \pm 0.307, P=0.877)$, dyslipidaemia (yes vs no, $n=42 / 45,-0.486$ vs $-0.545, P=0.403$ ), smoking history (yes vs no, $n=43 / 44,-0.542 \pm 0.348$ vs -0.498 $\pm 0.300, P=0.510$ ), and diabetes (yes vs no, $n=4 / 93$, $-0.795[-0.850 ;-0.73]$ vs $-0.560[-0.738 ;-0.302], P=$ 0.280 ) did not impact on the $\mathrm{CAD}_{238}$ score. There was also no difference in $\mathrm{CAD}_{238}$ score between men $(n=50)$ and women $(n=47)(-0.480 \pm 0.310$ vs. $-0.568 \pm 0.332, P$ $=0.178)$. In patients without angiographic evidence of CAD, the $\mathrm{CAD}_{238}$ score correlated with age as shown in Additional file 1: Figure S3. There was no statistically significant correlation between the $\mathrm{CAD}_{238}$ score and carotid intima media thickness in CAD patients $(n=73 ; \rho$ $=-0.078, P=0.510)$ and control subjects $(n=70 ; r=0.011$, $P=0.926)$ and thereby no evidence for influences of noncardiac atherosclerosis on the score.

In $77 \%$ of patients with CAD percutaneous coronary intervention (PCI) was performed prior to urine collection. Considering the correlation between the $\mathrm{CAD}_{238}$ and Gensini score we investigated the potential PCI effect on the urine polypeptide pattern. The Gensini score was recalculated by subtraction of stented artery segment 
Table 1 Cohort characteristics of stable angina patients with CAD and NCA

\begin{tabular}{|c|c|c|c|}
\hline & $\mathrm{CAD}, n=30$ & NCA, $n=30$ & $P$-value \\
\hline $\mathrm{CAD}_{238}$ score & $-0.487 \pm 0.341$ & $-0.612 \pm 0.269$ & 0.119 \\
\hline ACR (all > detection limit) & $0.9[0.6 ; 2.0]$ & $1.6[1.0 ; 3.4]$ & 0.036 \\
\hline Age, years & $55.1 \pm 6.0$ & $56.1 \pm 7.0$ & 0.539 \\
\hline Sex, $m / f$ & $16 / 14$ & $10 / 20$ & 0.192 \\
\hline $\mathrm{BMI}, \mathrm{kg} / \mathrm{m} 2$ & $27.9 \pm 4.2$ & $28.8 \pm 7.5$ & 0.605 \\
\hline $\mathrm{SBP}, \mathrm{mmHg}$ & $138 \pm 17$ & $138 \pm 19$ & 0.976 \\
\hline $\mathrm{DBP}, \mathrm{mmHg}$ & $78 \pm 10$ & $81 \pm 9$ & 0.205 \\
\hline Heart rate,/min & $57 \pm 9$ & $59 \pm 9$ & 0.321 \\
\hline Total cholesterol, mmol// & $4.3[3.8 ; 5.6]$ & $4.8[4.3 ; 5.7]$ & 0.077 \\
\hline LDL-cholesterol, mmol/l & $2.1[1.8 ; 3.3]$ & $2.4[2.0 ; 3.4]$ & 0.533 \\
\hline HDL-cholesterol, mmol/l & $1.2[0.9 ; 1.4]$ & $1.3[1.0 ; 1.6]$ & 0.286 \\
\hline Triglycerides, mmol// & $1.6[1.1 ; 2.1]$ & $1.7[1.1 ; 2.5]$ & 0.404 \\
\hline Hypertension history, \% & 77 & 57 & 0.438 \\
\hline CAD family history, $\%$ & 73 & 70 & 1.000 \\
\hline Diabetes history, \% & 20 & 13 & 0.299 \\
\hline Active smoking, $\%$ & 23 & 17 & 0.747 \\
\hline Statin, \% & 87 & 57 & 0.020 \\
\hline Aspirin, \% & 93 & 33 & $<0.001$ \\
\hline Beta-blocker, \% & 83 & 27 & $<0.001$ \\
\hline ACEI/ARB, \% & 40 & 33 & 0.789 \\
\hline Gensini-score & $40[25 ; 61]$ & 0 & - \\
\hline Corrected Gensini-score ₹ & $8[4 ; 40]$ & 0 & \\
\hline Carotid IMT, mm & $0.724[0.677 ; 0.802]^{a}$ & $0.753 \pm 0.092 \#$ & 0.444 \\
\hline
\end{tabular}

Data are given as mean \pm SD or median $[I C R]$ as appropriate. $P$-values are from Student's $t$-test, Mann-Whitney $U$-test, $C$ hi-square test or Fisher's exact test where appropriate. $A C E l$ angiotensin-converting enzyme inhibitor, $A C R$ albumin-creatinine ratio, $A R B$ angiotensin receptor blocker, $B M I$ body mass index, $C A D$ coronary artery disease, $D B P$ diastolic blood pressure, IMT intima-media thickness, NCA normal coronary arteries, HDL high-density lipoprotein, $L D L$ low-density lipoprotein, $S B P$ systolic blood pressure, $\neq$ Gensini-score after percutaneous intervention; ${ }^{a} n=29 ; \# n=28$

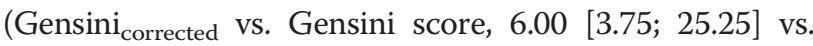
35.00 [22.63; 52.38], $P=0.001$ ). Using the median of the

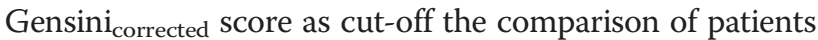
with CAD $(n=14)$ and NCA was repeated (Additional file 1: Figure $\mathrm{S} 4)$. The difference in $\mathrm{CAD}_{238}$ score between patients with CAD and a Gensini corrected $_{\text {score }}>6$ and those with NCA was statistically significant $(-0.395 \pm 0.386$ vs. $-0.612 \pm 0.269, P=0.036)$. We used a stepwise linear regression model with $\mathrm{CAD}_{238}$ score, age, gender and diabetes status as predictors of CAD to adjust for potential cofounding factors. The resulting model contained only the $\mathrm{CAD}_{238}$ score $(\beta=0.208 ; P=0.053)$ and gender $(\beta=0.131 ; P=0.025)$ and remained statistically significant $(P=0.014)$. Additionally, we correlated the corrected Gensini score with the $C_{23}$ score. The result $(\rho=0.560, P<0.001)$ was similar to the correlation between Gensini and $\mathrm{CAD}_{238}$ scores.

To estimate a potential value of urine proteomics for the identification of patients with prognostic relevant $\mathrm{CAD}$, we investigated the relationship between the
$\mathrm{CAD}_{238}$ score and specific angiographic findings in the complete CAD cohort. In accordance with current guidelines [13] prognostically relevant CAD was defined as left main stenosis $\geq 50 \%$, three-vessel disease or twovessel disease including the proximal left anterior descending artery (each with stenosis $\geq 70 \%$ ). The $\mathrm{CAD}_{238}$ score difference between prognostically relevant and non-relevant CAD was statistically significant $(n=64 / 32$; $0.059 \pm 0.442$ vs. $-0.361 \pm 0.416, P<0.001)$.

\section{Discussion}

The main finding of the present study is the significant association between the $\mathrm{CAD}_{238}$ score and extent of CAD. However, contrary to our hypothesis, the $\mathrm{CAD}_{238}$ score was not different between patients with chest pain who had CAD and patients with chest pain who had NCA. The retrospective design of our study may account for this apparently negative finding; correcting CAD extent for the treatment effect of PCI resulted in a statistically significant $\mathrm{CAD}_{238}$ score difference between patients and controls. 


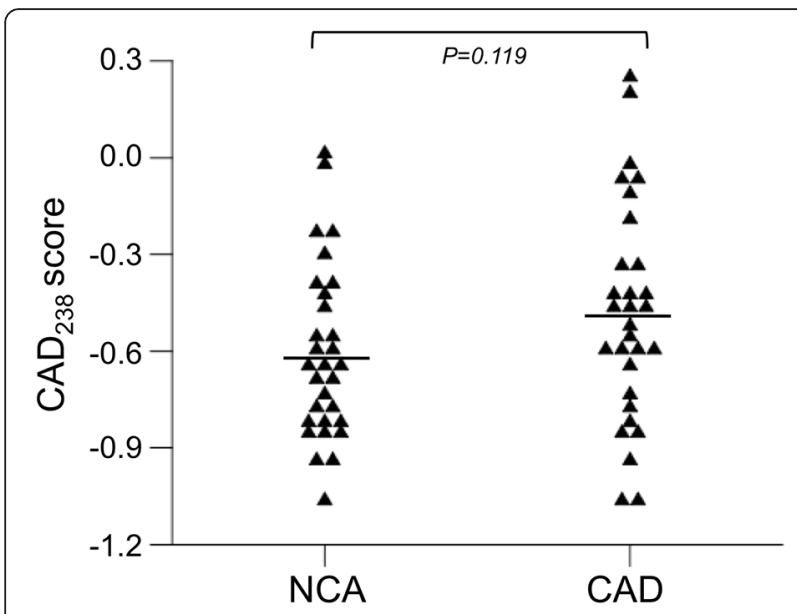

Fig. $1 \mathrm{CAD}_{238}$ score comparison between patients with NCA and CAD. Lines represent the mean. NCA normal coronary arteries, CAD coronary artery disease

\section{Urinary proteomics and CAD}

Urinary polypeptide patterns have been found to differentiate between patients with and without CAD in a variety of clinical situations such as unstable angina [14] and asymptomatic individuals with high cardiovascular risk [15]. To allow diagnosis of CAD independent of the clinical scenario we previously developed a urinary proteomics-derived pattern consisting of 238 polypeptides [6]. In the present study we evaluated the corresponding $\mathrm{CAD}_{238}$ score in patients with or without angiographic CAD.

In contrast to our previous studies in which the $\mathrm{CAD}_{238}$ score was developed and validated [6] we have chosen the present study design in order to look into less extreme phenotypes. The study represents a proof

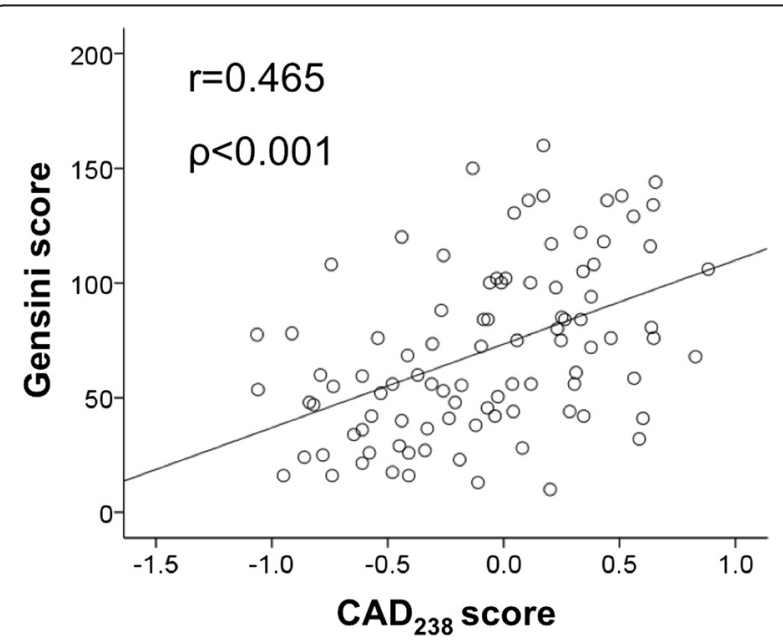

Fig. 2 Correlation between $C_{A D} 238$ score and the Gensini score. The Gensini score (y-axis) is plotted against the $\mathrm{CAD}_{238}$ score (x-axis) for 96 patients. Shown are the Spearman's correlation coefficient and the corresponding $P$-value of concept study closer to clinical practice [16]. The diagnostic validation of the $\mathrm{CAD}_{238}$ score [16] for instance in patients with intermediate cardiovascular risk and stable angina [1,2] does however require further investigations and further refinement of the CAD specific urine polypeptide pattern.

Scoring systems of coronary angiograms target different qualities. The Syntax score, for instance, evaluates CAD complexity [17]. For this study we chose the Gensini Score [7] in order to quantify CAD extent/severity. In the past the Gensini score has been associated with inflammation [18], systemic atherosclerosis [19], peripheral vascular disease [20], renal impairment [21] and the chromosome 9p21 risk locus [22] emphasising its value in CAD assessment.

Gensini scores in patients with CAD and stable angina in the present study were lower than those in patients awaiting $\mathrm{CABG}$ in our previous biomarker validation study, confirming the expected less pronounced coronary atherosclerosis in the present cohort [6]. Also, the majority of patients with CAD and stable angina underwent PCI including stent insertion prior to urine collection. Intervention leads to extensive arterial wall remodeling and neointima formation $[23,24]$. The altered physiology of the stented artery segment is therefore expected to impact on the $\mathrm{CAD}_{238}$ score. We therefore accounted for the reduction of atherosclerotic wall segments in contact with the blood stream after PCI. The difference in $\mathrm{CAD}_{238}$ score between control subjects and patients with remaining significant coronary artery atheroma after $\mathrm{PCI}$, represented by a Gensini score $>6$, was statistically significant. The intervention probably contributed to a "healthier" $\mathrm{CAD}_{238}$ score in patients with stable angina and CAD than in those scheduled for surgical coronary revascularization who were previously studied.

We found, however, a strong correlation between the Gensini score and the $\mathrm{CAD}_{238}$ score. The Gensini score was designed to reflect on the number of diseased coronary arteries, their importance regarding dependent myocardial mass and the extent of arterial narrowing [7]. The score therefore provides a measure of CAD extent. In extensive CAD the surface area of plaque will be larger. Therefore more atherosclerosis related peptides will enter the blood stream and can be subsequently detected in the urine.

In our cohort carotid intima-media thickness and the $\mathrm{CAD}_{238}$ score were not correlated. As carotid intimamedia thickness is a marker of early atherosclerosis, the finding suggests the independence of the $\mathrm{CAD}_{238}$ score from non-cardiac atherosclerosis.

Next to the diagnosis of significant CAD in stable angina patients, the identification of prognostic relevant CAD holds clinical value. Several predictors of prognostically relevant $\mathrm{CAD}$ are known [25]. Considering the 
significant $\mathrm{CAD}_{238}$ score difference between prognostically relevant and non-relevant CAD in our cohort, urine proteomics has also potential to identify patients with such disease and to direct therapies to high-risk patients.

\section{Collagen turnover assessment by urinary proteomics}

Most peptides in the $\mathrm{CAD}_{238}$ panel were collagen fragments [6]. As the collagen content in artery walls increases with age [26], leading to increased arterial wall stiffness, this might explain the score's correlation with age. Altered degradation of Type 1 and 3 collagens in atheromatous plaque [27] might also explain the predominance of collagen fragments, especially since plaque burden increases with age [28]. In older subjects the collagen concentration in atheromatous plaque increases in areas close to the arterial lumen [29] and is therefore in closer contact with the blood stream.

Synthesis or degradation of collagens is slow in a healthy arterial system [30], which may imply decreased levels of collagen fragments in the blood stream of healthy individuals. In atheromatous plaque the main component of the fibrous cap, the region in contact with the circulating blood, consists of types 1 and 3 collagens [31]. Atherosclerosis causes an increased synthesis and degradation of many matrix components [32], and the $\mathrm{CAD}_{238}$ score derived from urinary proteomics may represent a measure of collagen turnover and thereby represent a biomarker of cardiovascular disease.

Significant CAD not only affects the coronary vessel walls but also the myocardium by transient or permanent ischemia; for example in myocardium with exercise induced perfusion deficits or hibernating myocardium. Considering the statistically significant differences in $\mathrm{CAD}_{238}$ score after correction of the Gensini score as well as the high $\mathrm{CAD}_{238}$ score in prognostically relevant CAD, myocardial ischemia on its own or in addition to cardiac atherosclerosis could potentially contribute to the urinary proteome in patients with CAD. Transient [33] or permanent [34] inadequate myocardial perfusion leads to localized inflammation and increased interstitial fibrosis. As myocardial fibrosis is characterized by accumulation of collagen types 1 and 3 within the intercellular space [35], this quantity change implies increased collagen degradation and hence a rise in collagen fragments.

\section{Study limitations}

The main finding of the present study, i.e. the relationship between $C_{A D} D_{238}$ score and CAD extent, is at the same time the major limitation of urine proteomics as a diagnostic tool for CAD. Indeed, our present findings suggest that the CAD-specific urinary polypeptide pattern is related to CAD extent and it should of course be noted that normal coronary angiography results do not exclude early forms of coronary atherosclerosis. The polypeptide pattern could in addition to or instead of coronary atherosclerosis identify flow limiting CAD with consecutive myocardial fibrosis. Therefore, additional investigations are required to determine the origin of the $\mathrm{CAD}_{238}$ score.

A further limitation of the present study is its retrospective design. Urine samples were collected after coronary angiography, which included PCI in $77 \%$ of the cases. It is therefore possible that the $\mathrm{CAD}_{238}$ score could differentiate between patients with stable angina with and without CAD in a prospective study if the samples had been taken prior to PCI.

\section{Conclusions}

We have previously shown that polypeptide patterns derived form urine proteomics provides good diagnostic accuracy for severe CAD. The $\mathrm{CAD}_{238}$ score is, however, of limited diagnostic value in patients with stable angina-like chest pain who have less extensive CAD. Furthermore, the $\mathrm{CAD}_{238}$ score reflects on CAD extent suggesting that the score has potential for prognostication but is less useful for diagnosis in patients with stable angina if not complemented by other diagnostic tests. However, our data support the association of urinary peptides with $C A D$ and provide a rationale for further development of diagnostic proteomic biomarkers.

\section{Ethics approval and consent to participate}

All participants gave written informed consent. The study was approved by the West of Scotland Research Ethics Committee and is in keeping with the principles of the Declaration of Helsinki.

\section{Consent for publication}

Not applicable.

\section{Availability of data and materials}

Details on the peptides that determine the $\mathrm{CAD}_{238}$ score have been published previously [6]. Further data are available on request from the corresponding author.

\section{Additional file}

Additional file 1: Table S1. Cohort characteristics of patients with
severe CAD planned to undergo CABG surgery and age matched healthy
volunteers. Table S2. Cohort characteristics of combined patients with
CAD and controls (NCA or healthy volunteers). Figure S1. Flowchart of
the DiCADu study design and recruitment process. CAD, coronary artery
disease; NCA, normal coronary arteries. Figure S2. Effect of drug
treatment on the CAD 238 score. For comparisons Student's t-test was
used. ACEl, angiotensin-converting enzyme inhibitor; ARB, angiotensin
receptor blocker; CCB, calcium channel blocker; BB, beta-blocker. Figure
S3. Correlation between age and CAD 238 score in control subjects. The
Pearson correlation coefficient and the corresponding P-value are shown.
Figure S4. Comparison of CAD 238 SCore between patients with NCA and
CAD corrected for remaining coronary atherosclerosis after percutaneous
coronary intervention. Lines represent the median. NCA, normal coronary
arteries. (DOC 1181 kb)




\section{Abbreviations}

ACEl: angiotensin-converting enzym; ACR: albumin-creatinine ratio; ARB: angiotensin receptor blocker; BMI: body mass index; CABG: coronary artery bypass graft; CAD: coronary artery diseasse; DBP: diastolic blood pressure; HDL: high-density lipoprotein; ICR: interquartile range; IMT: intimamedia thickness; LDL: low-density lipoprotein; NCA: normal coronary arteries; PCl: percutaneous coronary intervention; SBP: systolic blood pressure.

\section{Competing interests}

There are no competing interests to declare in relation to this manuscript.

\section{Authors' contributions}

UN conceived the study, obtained ethical approval, recruited the study subjects, conducted the study visits, performed the statistical analysis and drafted the manuscript. TK carried out the proteomics measurement and analysis and participated in the manuscript drafting. HM participated in the proteomics measurements and analysis and the manuscript drafting. SHR participated in the recruitment of study subjects and conduction of study visits. EO participated in the conduction of study visits. DMC and JAD participated in recruitment of study subjects and conduction of study visits. AFD, CB and KGO participated in study design and manuscript drafting. CD conceived the study, obtained ethical approval and drafted the manuscript. All authors read and approved the final manuscript.

\section{Acknowledgements}

Not applicable.

\section{Funding}

The study was supported by the European Union's Sixth Framework Programme Network of Excellence InGenious HyperCare (grant agreement LSHM-CT-2006-037093), the Seventh Framework Programme Collaborative Projects EU-MASCARA (grant agreement 278249) and HOMAGE (grant agreement 305507) and the British Heart Foundation Chair and Programme Grant RG/07/005/23633.

\section{Author details 8TA, UK. ${ }^{2}$ mosaiques diagnostics GmbH, Rotenburger Str. 20, 30659 Clydebank G81 4DY, UK. \\ Received: 31 December 2015 Accepted: 14 April 2016 Published online: 19 April 2016}

'BHF Glasgow Cardiovascular Research Centre, Institute of Cardiovascular and Medical Sciences, University of Glasgow, 126 University Place, Glasgow G12 Hannover, Germany. ${ }^{3}$ Golden Jubilee National Hospital, Agamemnon Street,

\section{References}

1. Fox K, Garcia MA, Ardissino D, Buszman P, Camici P, Crea F, Daly C, De Backer G, Hjemdahl P, Lopez-Sendon J, Marco J, Morais J, Pepper J, Sechtem U, Simoons M, Thygesen K, Priori SG, Blanc JJ, Budaj A, Camm J, Dean V, Deckers J, Dickstein K, Lekakis J, McGregor K, Metra M, Morais J, Osterspey A, Tamargo J, Zamorano JL. Guidelines on the management of stable angina pectoris: executive summary: the Task Force on the Management of Stable Angina Pectoris of the European Society of Cardiology. Eur Heart J. 2006;27: 1341-81.

2. Fihn SD, Gardin JM, Abrams J, Berra K, Berra K, Blankenship JC, Dallas AP, Douglas PS, Foody JM, Gerber TC, Hinderliter AL, King SB 3rd, Kligfield PD, Krumholz HM, Kwong RY, Lim MJ, Linderbaum JA, Mack MJ, Munger MA, Prager RL, Sabik JF, Shaw L, Sikkema JD, Smith CR Jr, Smith SC Jr, Spertus JA, Williams SV. 2012 ACCF/AHA/ACP/AATS/PCNA/SCAI/STS Guideline for the diagnosis and management of patients with stable ischemic heart disease: a report of the American College of Cardiology Foundation/ American Heart Association Task Force on Practice Guidelines, and the American College of Physicians, American Association for Thoracic Surgery, Preventive Cardiovascular Nurses Association, Society for Cardiovascular Angiography and Interventions, and Society of Thoracic Surgeons. Circulation. 2012;126:3097-137.

3. Delles C, Neisius U, Carty DM. Proteomics in hypertension and other cardiovascular diseases. Ann Med. 2012;44:S55-64.

4. Decramer S, Gonzalez de Peredo A, Breuil B, Mischak H, Monsarrat B, Bascands JL, Schanstra JP. Urine in clinical proteomics. Mol Cell Proteomics. 2008;7:1850-62.
5. Zimmerli LU, Schiffer E, Zurbig P, Good DM, Kellmann M, Mouls L, Pitt AR, Coon JJ, Schmieder RE, Peter KH, Mischak H, Kolch W, Delles C, Dominiczak AF. Urinary proteomic biomarkers in coronary artery disease. Mol Cell Proteomics. 2008;7:290-8.

6. Delles C, Schiffer E, von Zur Muhlen C, Peter K, Rossing P, Prving HH, Dymott JA, Neisius U, Zimmerli LU, Snell-Bergeon JK, Maahs DM, Schieder RE, Mischak H, Dominiczak AF. Urinary proteomic diagnosis of coronary artery disease: identification and clinical validation in 623 individuals. J Hypertens. 2010;28:2316-22.

7. Gensini GG. A more meaningful scoring system for determining the severity of coronary heart disease. Am J Cardiol. 1983;51:606.

8. Touboul P, Hennerici MG, Meairs S, Adams H, Amarenco P, Bornstein N, Csiba L, Desvarieux M, Ebrahim S, Fatar M, Hernandez R, Jaff M, Kownator S, Prati P, Rundek T, Sitzer M, Schminke U, Tardif JC, Taylor A, Vicaut E, Woo KS, Zannad F, Zureik M. Mannheim carotid intima-media thickness consensus (2004-2006). An update on behalf of the Advisory Board of the 3rd and 4th Watching the Risk Symposium, 13th and 15th European Stroke Conferences, Mannheim, Germany, 2004, and Brussels, Belgium, 2006. Cerebrovasc Dis. 2007;23(1):75-80.

9. Theodorescu D, Wittke S, Ross MM, Walden M, Conaway M, Just I, Mischak $H$, Frierson HF. Discovery and validation of new protein biomarkers for urothelial cancer: a prospective analysis. Lancet Oncol. 2006;7:230-40.

10. Wittke S, Mischak H, Walden M, Kolch W, Radler T, Wiedermann K. Discovery of biomarkers in human urine and cerebrospinal fluid by capillary electrophoresis coupled to mass spectrometry: towards new diagnostic and therapeutic approaches. Electrophoresis. 2005;26:1476-87.

11. Mischak H, Vlahou A, loannidis JP. Technical aspects and inter-laboratory variability in native peptide profiling: the CE-MS experience. Clin Biochem. 2013:46:432-43.

12. Jantos-Siwy J, Schiffer E, Brand K, Schumann G, Rossing K, Delles C, Mischak $\mathrm{H}$, Metzger J. Quantitative urinary proteome analysis for biomarker evaluation in chronic kidney disease. J Proteome Res. 2009;8:268-81.

13. Levine GN, Bates ER, Blankenship JC, Bailey SR, Bittl JA, Cercek B, Chambers CE, Ellis SG, Guyton RA, Hollenberg SM, Khot UN, Lange RA, Mauri L,Mehran R, Moussa ID, Mukherjee D, Nallamothu BK, Ting HH, Jacobs AK, Anderson $J$, Albert N, Creager MA, Ettinger SM, Guyton RA, Halperin JL, Hochman JS, Kushner FG, Ohman EM, Stevenson W,Yancy CW, Holmes DR Jr, Lewin JC, Wright J, May C, Barrett EA, Bradfield L, Keller S, Welsh JM, Mukherjee D, Sacco RL, Brown N,Robertson RM, Whitman GR, Stewart MD. 2011 ACCF/ AHA/SCAI Guideline for Percutaneous Coronary Intervention: executive summary: a report of the American College of Cardiology Foundation/ American Heart Association Task Force on Practice Guidelines and the Society for Cardiovascular Angiography and Interventions. Cath Cardiovasc Interv. 2012;79:453-95.

14. von zur Mühlen C, Schiffer E, Zuerbig P, Kellmann M, Brasse M, Meert N, Vanholder RC, Dominiczak AF, Chen YC, Mischak H, Bode C, Peter K. Evaluation of urine proteome pattern analysis for its potential to reflect coronary artery atherosclerosis in symptomatic patients. J Proteome Res. 2009:8:335-45.

15. Snell-Bergeon JK, Maahs DM, Ogden LG, Kinney GL, Hokanson JE, Schiffer E, Rewers M, Mischak $\mathrm{H}$. Evaluation of urinary biomarkers for coronary artery disease, diabetes, and diabetic kidney disease. Diabetes Technol Ther. 2009;11:1-9.

16. Hlatky MA, Greenland P, Arnett DK, Ballantyne CM, Criqui MH, Elkind MS, Go AS, Harrell FE Jr, Hong Y, Howard BV, Howard VJ, Hsue PY, Kramer CM,McConnell JP, Normand SL, O'Donnell CJ, Smith SC Jr, Wilson PW; American Heart Association Expert Panel on Subclinical Atherosclerotic Diseases and Emerging Risk Factors and the Stroke Council. Criteria for evaluation of novel markers of cardiovascular risk: a scientific statement from the American Heart Association. Circulation. 2009;1 19:2408-16.

17. Farooq V, Head SJ, Kappetein AP, Serruys PW. Widening clinical applications of the SYNTAX Score. Heart. 2014;100:276-87.

18. Demir K, Avci A, Altunkeser BB, Yilmaz A, Keles F, Ersecgin A. The relationship between neutrophil-to-lymphocyte ratio and coronary chronic total occlusions. BMC Cardiovasc Disord. 2014;14:130.

19. Adams MR, Nakagomi A, Keech A, Robinson J, McCredie R, Bailey BP, Freedman SB, Celermajer DS. Carotid intima-media thickness is only weakly correlated with the extent and severity of coronary artery disease. Circulation. 1995;92(8):2127-34.

20. Papamichael CM, Lekakis JP, Stamatelopoulos KS, Papaioannou TG, Alevizaki MK, Cimponeriu AT, Kanakakis JE, Papapanagiotou A, Kalofoutis AT, Stamatelopoulos SF. Ankle-brachial index as a predictor of the extent of 
coronary atherosclerosis and cardiovascular events in patients with coronary artery disease. Am J Cardiol. 2000;86(6):615-8.

21. Stamatelopoulos KS, Lekakis JP, Tseke P, Ikonomidis I, Kollias GE, Alevizaki M, Kanakakis I, Voidonikola P, Zakopoulos N, Papamichael CM. Differential associations of renal function with coronary and peripheral atherosclerosis. Int J Cardiol. 2009;135(2):162-4.

22. Patel RS, Su S, Neeland IJ, Ahuja A, Veledar E, Zhao J, Helgadottir A, Holm H, Gulcher JR, Stefansson K, Waddy S, Vaccarino V, Zafari AM, Quyyumi AA. The chromosome 9p21 risk locus is associated with angiographic severity and progression of coronary artery disease. Eur Heart J. 2010;31(24):3017-23.

23. Goel SA, Guo LW, Liu B, Kent KC. Mechanisms of post-intervention arterial remodelling. Cardiovasc Res. 2012;96:363-71.

24. Welt FG, Rogers C. Inflammation and restenosis in the stent era. Arterioscler Thromb Vasc Biol. 2002;22:1769-76.

25. D'Ascenzo F, Presutti DG, Picardi E, Moretti C, Omedè P, Sciuto F, Novara M, Yan AT, Goodman S, Mahajan N, Kosuge M, Palazzuoli A, Jong GP, Isma'eel H, Budoff MJ, Rubinshtein R, Gewirtz H, Reed MJ, Theroux P, Biondi-Zoccai G, Modena MG, Sheiban I, Gaita F. Prevalence and non-invasive predictors of left main or three-vessel coronary disease: evidence from a collaborative international meta-analysis including 22740 patients. Heart. 2012;98(12):914-9.

26. Greenwald SE. Ageing of the conduit arteries. J Pathol Jan. 2007;211:157-72.

27. Sukhova GK, Schonbeck U, Rabkin E, Schoen FJ, Poole AR, Billinghurst RC, Libby P. Evidence for increased collagenolysis by interstitial collagenases-1 and -3 in vulnerable human atheromatous plaques. Circulation. 1999;99:2503-9.

28. Pasternak RC, Criqui MH, Benjamin EJ, Fowkes FG, Em I, McCullough PA, et al. Atherosclerotic vascular disease conference: writing group I: epidemiology. Circulation. 2004;109:2605-12.

29. Stary HC. The sequence of cell and matrix changes in atherosclerotic lesions of coronary arteries in the first forty years of life. Eur Heart J. 1990;11 Suppl E:3-19.

30. Seyer JM, Kang AH. Connective tissues of the subendothelium. In: Loscalzo J, Creager MA, Dzau VJ, editors. Vascular medicine. Boston, Mass: Little Brown and Co; 1992. p. 47-78.

31. Shekhonin BV, Domogatsky SP, Idelson GL, Koteliansky VE, Rukosuev VS Relative distribution of fibronectin and type I, III, IV, V collagens in normal and atherosclerotic intima of human arteries. Atherosclerosis. 1987:67:9-16.

32. Lee RT, Libby P. The unstable atheroma. Arterioscler Thromb Vasc Biol. 1997; 17:1859-67.

33. Dewald O, Frangogiannis NG, Zoerlein M, Duerr GD, Klemm C, Knuefermann P, Taffet G, Michael LH, Crapo JD, Welz A, Entman ML. Development of murine ischemic cardiomyopathy is associated with transient inflammatory reaction and depends on reactive oxygen species. Proc Natl Acad Sci U S A. 2003;100(5):2700-5.

34. Elsässer A, Schlepper M, Klövekorn WP, Cai WJ, Zimmermann R, Müller KD, Strasser R, Kostin S, Gagel C, Münkel B, Schaper W, Schaper J. Hibernating myocardium: an incomplete adaptation to ischemia. Circulation. 1997;96(9): 2920-31.

35. López B, González A, Ravassa S, Beaumont J, Moreno MU, San José G, Querejeta R, Díez J. Circulating biomarkers of myocardial fibrosis: the need for a reappraisal. J Am Coll Cardiol. 2015;65(22):2449-56.

\section{Submit your next manuscript to BioMed Central and we will help you at every step:}

- We accept pre-submission inquiries

- Our selector tool helps you to find the most relevant journal

- We provide round the clock customer support

- Convenient online submission

- Thorough peer review

- Inclusion in PubMed and all major indexing services

- Maximum visibility for your research

Submit your manuscript at www.biomedcentral.com/submit

C Biomed Central 